\title{
Reggio Emilia, Maria Montessori, and John Dewey: Dispelling Teachers' Misconceptions and Understanding Theoretical Foundations
}

\author{
Arleen Theresa Dodd-Nufrio
}

Published online: 17 March 2011

(C) Springer Science+Business Media, LLC 2011

\begin{abstract}
During the past century Loris Malaguzzi (1920-1994), a principal figure in the establishment and creation of the preschools of Reggio Emilia, Italy, was one of the seminal thinkers in early childhood education. The influence of John Dewey, one of the most important American philosophers, is visible in contemporary early childhood classrooms of Reggio Emilia. However, as this editorial contends, in the author's experience, many pre-service teachers have the misconception that the two programs that originated in Italy_-Maria Montessoir and Reggio Emiliaare synonymous. This editorial discusses another connection; namely, the relationship between John Dewey's philosophy of education and the pedagogy of Reggio Emilia preschools. Pre-service teachers' understanding of Dewey's theory and the Reggio Emilia experience makes an important contribution to the development of their personal teaching philosophy and understanding of best practices in the field.
\end{abstract}

Keywords Reggio Emilia · Preschool · John Dewey · Early childhood education

When I asked a group of undergraduate early childhood majors, "Who knows anything about Reggio Emilia?" some of them responded, "I think they're like Maria Montessori schools." Evidently, the assumption that all programs that originated in Italy are the same is not unique to this population. When I participated in a universitysponsored study tour of preschools in Brescia, the faculty member/guide was unfamiliar with the Reggio Emilia

A. T. Dodd-Nufrio ( $\square)$

The State University of New York College at Old Westbury, Old Westbury, NY, USA

e-mail: arleendodd@verizon.net preschools and their theoretical foundation and many of the graduate students of early childhood education participating in this tour held the misconception that Montessori and Reggio were synonymous.

Since the 1990s the preschools of Reggio Emilia, Italy became increasingly known in the early childhood education community yet little is known about the theoretical underpinnings of the program. As this editorial will describe, it is John Dewey's philosophy that is most visible in the early childhood classrooms of Reggio Emilia.

By virtue of their shared cultural context, Reggio Emilia and Montessori do share similarities. ${ }^{1}$ What is less well understood is the philosophical foundation of the Reggio Emilia preschools. This editorial examines John Dewey's education philosophy and its influence on the Reggio Emilia experience and pedagogy; it also shows how these connections can enhance student learning and teaching practices in preschools in the United States.

\section{Background on Reggio Emilia and its Preschools}

Reggio Emilia, a city of 140,000 outside of Milan, Italy, is known for its commitment to quality care and education for children birth to age six. Since 1963 the city government has assumed the responsibility of running the schools started by the parents after WWII and has opened others. The schools of Reggio Emilia are built upon a social constructivist framework inspired by John Dewey, Jean Piaget, Lev Vygotsky, Jerome Bruner (Gandini 1993). This socio-constructivist model states that both children and adults co-

\footnotetext{
1 This writer assigns the following reading to early childhood education students for a brief comparison of Reggio Emilia and Montessori; Edwards(2002).
} 
construct their knowledge through interactions with people and the environment. The influence of John Dewey, one of the most influential American philosophers, is visible in the early childhood classrooms of Reggio Emilia. Lella Gandini (1993), who is recognized as a world leader on the Reggio Emilia approach, contends that early Reggio Emilia educators were avid followers of John Dewey. Greenberg (1993) also makes the connection between Dewey, Malaguzzi and Reggio Emilia with the statement,

Other major philosophers and theoreticians such as Piaget and Vygotsky did not provide direct guidance about how to implement their theories in schools; although Dewey related his theories to practice more clearly, his school did not endure for many decades $\{$ sic $\} .{ }^{2}$ Unlike those who inspired and influenced his work, Malaguzzi developed his theory and philosophy of early childhood education from direct practice in schools for infants, toddlers, and preschoolers over a 30 year period. Lilian Katz has observed that in Reggio Emilia, practice drives theory, rather than the opposite, and may even be ahead of development. (p. 9)

One of the key principles of the Reggio Emilia schools is a deeply held belief in the positive image of the child. It builds on the premise that each child has the desire to connect with others, to engage in learning, and to enter into a relationship with their environment. John Dewey founded the Chicago Laboratory School based on the view of the child as a growing and changing being that requires active learning experiences of immediate interest and personal involvement (Weiss et al. 2005). Likewise, Reggio Emilia educators contend: that preschool education is a right not a privilege; that all children have the potential to learn; and, in keeping with Dewey's philosophy, that children are architects of their own learning, Rinaldi (2005) supports the belief that the Reggio Emilia experience is not a model but a culture or right.

The socio-constructivist model promotes an image of the child as a capable participant in learning. In Reggio Emilia the image of the child is one of a confident, capable person. Reggio Emilia educators believe that the school is not a place of transmission of knowledge. Rather it is an environment that allows the child to be a producer of culture and knowledge - the child is a knowledge maker. Both the school and children are creators of culture. Likewise, Rinaldi (2005) believes that children are the best expression of humanity and are citizens of the present not just the future. Like Emilia educators she believes that

\footnotetext{
2 The Laboratory School founded by John and Alice Dewey at the University of Chicago was directed by him for less than 8 years (from 1896-1904) however it is still in existence today.
}

education is the process of building knowledge and abilities.

Dewey's principles are evident in Reggio Emilia preschool values and practices. For many in the field Dewey's principles are not new. Many of the basic ideas that inspired the Reggio Emilia educators originated in the United States. Gandini (1993) believes that they have returned to their point of origin. Valentine (1999) also believes that Dewey's pedagogy and view of education is found in the classrooms and community of Reggio Emilia,

unlike other pedagogies that can be guilty of treating early infancy as a preparation for later childhood and adulthood, and consequently seeing nursery education as a kind of antechamber to later stages of formal education, the Reggio Approach considers early infancy to be a distinct developmental phase in which children demonstrate an extraordinary curiosity about the world. (p. 5)

\section{Perspectives on Evaluation}

Reggio Emilia preschools mirror Dewey's philosophy of evaluation as well. Dewey was not opposed to testing or evaluation per se, but weary of the way testing or evaluation is generally used in schools. As explained in Democracy and Education (1916):

How one person's abilities compare in quantity with those of another is none of the teacher's business. It is irrelevant to his work. What is required is that every individual shall have opportunities to employ his own powers in activities that have meaning. Mind, individual method, originality (these are convertible terms) signify the quality of purposive or directed action. If we act upon this conviction, we shall secure more originality even by the conventional standard than now develops. Imposing an alleged uniform general method upon everybody breeds mediocrity in all but the very exceptional. (p. 336)

Edwards (2002) points out that policy makers in the United States "ask for new studies of...Reggio Emilia schools that would measure lasting child-related outcomes and evaluate program quality based on external criteria" (p. 10). Child outcome research is not intrinsic to the way educators work in Reggio Emilia. They have never done studies to evaluate the efficacy of their programs. Amelia Gambetti, Executive Coordinator of The Istituzione for Schools and Infant toddler Centers of the Municipality of Reggio Emilia and former teacher, stated that their preschoolers often perform better in schools than others, "but school isn't everything" (cited in Stanley 2001). She 
pointed out that in the last 4 years in Reggio Emilia a child has never revisited a setting been retained in the same grade (Gambetti 2003). Her explanation is that "there is absolutely no need because we don't teach to children's weaknesses, we teach to children's strengths." Gandini (1993) added, "Thirty years of successful experience with schools for about half of the children in a city of 130,000 inhabitants has created powerful results..." (pp. 4-5).

Rinaldi (2005) pointed out that in Italian assessment means to give value. Educators need to decide from a philosophical and ethical aspect if assessment interferes or enriches. She asks, "Why do we use outcomes? Factories have input and output. Is outcome the best word we can use?" Educators should focus on process folios not portfolios because it is how we learned not what we learned.

Rinaldi (2005) is also opposed to longitudinal studies "I don't have to guarantee the school as a product but a community of learning. I don't have to sell it. We have second and third generation graduates now. We don't understand what you search for; we understand the quality of the community."

Weiss et al. (2005) believe that "Dewey would look at the standards movement today and see that is has evolved into an absurdity" (p. 16). They state, "One important legacy of Dewey's thinking for today's students suggests that standards can well serve students and not the other way around" (p. 17). "The place of measurement of achievements as a theory of education is very different in a static educational system from what it is in one which is dynamic, or in which the ongoing process of growing is the important thing (Progressive Education and the Science of Education)." Darling-Hammond and Sclan (1996) pointed out, "An alternative approach to reform uses standards and assessments as a means of giving feedback to educators and as tools for organizing student and teacher learning, rather than as a sledgehammer to beat schools into change" (p. 241).

Since many early childhood educators have explored the implications of the Reggio Emilia experience for the theory, practice, and improvement of United States early childhood education, New (2000) raises a new question. She asks, "How can American educators recognize and use what Reggio Emilia has accomplished in their 50 years of development?" (p. 2). Reggio Emilia educators stress that they cannot teach us how to "do," adapt, or interpret Reggio in the United States. Amelia Gambetti (2003) emphasizes that Reggio Emilia is not an approach but an experience. Both Gardner (1998) and Firlik (1994) believe that one cannot simply take the Reggio Emilia program and transplant it in the United States; it must be reinterpreted and reinvented in the context of American culture.
Dewey's belief in context never wavered even when, later in his life, he adjusted his belief from believing that schools should be the primary change for social progress and reform to schools being necessary for social progress and reform (Eldridge 1998). The issue of context is seen in the way Dewey understood schools and society. If the Reggio Emilia experience is consonant with Dewey's notion of context, educators must pay attention to the unique experience of children. This is an experience that can only be understood within the context of each child.

Through a strong commitment and cooperation of educators, parents, and the community, Reggio Emilia's exemplary program has made significant impact on early childhood education in the United States (Desouza 1999). Recognizing the influence of American educational philosopher John Dewey on Reggio Emilia preschools can help the teaching community understand how to develop more skilled, competent, and caring teaching professionals.

\section{References}

Desouza, J. M. S. (1999). Early childhood science: Adopting the Reggio Emilia approach. (ERIC Document Reproduction Service No. ED442664 SE063793).

Dewey, J. (1916). Democracy and education. New York, NY: Simon \& Schuster.

Edwards, C. P. (2002). Three approaches from Europe: Waldorf, Montessori and Reggio Emilia. Early Childhood Research and Practice, 4 (1). Retrieved from http://ecrp.uiuc.edu/v4n1/ edwards.html.

Eldridge, M. (1998). Transforming experience. Nashville, TN: Vanderbilt University Press.

Firlik, R. J. (1994). Reggio Emilia, Italy preschools: The synergies of theory and practice. (ERIC Document Reproduction Service No. ED382313 PS022958).

Gambetti, A. (2003, March). Lecture given during the American Reggio Children Study tour.

Gandini, L. (1993). Fundamentals of the Reggio Emilia approach to early childhood education. Young Children, 49(1), 4-8.

Gardner, H. (1998). In Impact. [Television series episode]. Atlanta, GA: Cable News Network.

Greenberg, P. (1993). Editor's note. Young Children, 49(1), 9.

New, R. S. (2000). Reggio Emilia: Catalyst for change and conversation. ERIC Digest. (ERIC Document Reproduction Service No. ED447971 PS029100).

Rinaldi, C. (2005, October). The pedagogy of listening. Lecture given during the Pedagogy of Listening Conference, October 7-8, 2005, Miami, FL.

Stanley, A. (2001, April 25). French and Italian preschools: Models for the U. S. The New York Times, p. 4.

Valentine, M. (1999). The Reggio Emilia approach to early years education. North Lanarkshire, Scotland: Scottish Consultative Council on the Curriculum.

Weiss, S. G., DeFalco, A. A., \& Weiss, E. M. (2005). Essays in education. Retrieved September 1, 2005, from http://www.uaca. edu/essays/vol142005/defalco.pdf. 